\title{
Sub- and supercritical esterification of palm fatty acid distillate with carbohydrate- derived solid acid catalyst
}

\begin{abstract}
The esterification of palm fatty acid distillate (PFAD) in supercritical methanol was investigated by using carbohydrate-derived solid acid catalyst. The catalysts were prepared by sulfonation of incomplete carbonized glucose and starch, which had been coded as sulfonated-ICG and sulfonated-ICS, respectively. The contents of fatty acid methyl ester (FAME) and its yield were determined by using gas chromatography techniques. The effects of sub- and supercritical operating conditions such as methanol/PFAD molar ratio, catalyst amount, reaction temperature and reaction time were analyzed to determine their optimum operating conditions. At optimum reaction temperature of $290{ }^{\circ} \mathrm{C}$, methanol/PFAD molar ratio of 6/1, catalyst amount of $1 \mathrm{wt} . \%$ and 5 min reaction time, the esterification of PFAD in supercritical methanol with the presence of sulfonated-ICS and -ICG catalysts resulted $97.3 \%$ and $95.4 \%$ of FAME; both catalysts yield significantly higher percentages compared to uncatalyzed reaction. Alongside of its potential in enhancing the efficiency of production process, the utilization of carbohydrate-derived solid acid catalyst in supercritical methanol method had also resulting fast reaction and energy saving.
\end{abstract}

Keyword: Esterification; Supercritical methanol; Palm fatty acid distillate; Carbohydratederived solid acid catalyst; Fatty acid methyl ester 